\section{Anticonvulsant Agents for the Management of Benzodiazepine Dependence}

\author{
Marta Marín-Mayor ${ }^{1}$, Francisco López-Muñoz ${ }^{2,3,4 *}$ and Gabriel \\ Rubio ${ }^{1,4,5}$ \\ ${ }^{1}$ Psychiatry Service, "Doce de Octubre" University Hospital, Madrid, Spain \\ ${ }^{2}$ Department of Biomedical Sciences (Pharmacology Area), Faculty of \\ Medicine and Health Sciences, University of Alcalá, Madrid, Spain \\ ${ }^{3}$ Faculty of Health Sciences, Camilo José Cela University, Madrid, Spain \\ 4"Hospital 12 de Octubre" Research Institute, Madrid, Spain \\ ${ }^{5}$ Department of Psychiatry, Complutense University, Madrid, Spain
}

\begin{abstract}
\section{Introduction}

Chronic use of Benzodiazepines (BZDs) can lead to tolerance and dependence, as indicated by a BZD Withdrawal Syndrome (BWS). In general, it is preferred a gradual than an abrupt tapering of BZDs as a first step in the treatment of BZD Dependence (BD). In addition, a great variety of agents have been used as adjuvant medication for BD. Recently, research has focused in the use of Anticonvulsant (AC) drugs. The aim of this article is to review the use of $A C$ in the management of BWS and BD.

\section{Methods}

MEDLINE and the Cochrane were searched, selecting studies from 1980 until 2014, in which a pharmacological intervention with classic and new AC was made for discontinuing long-term BZD use. Results

In regard to classic $\mathrm{AC}$, there were identified 10 studies related to carbamazepine and 4 studies related to valproate. On one hand, whereas there is a great body of research involving carbamazepine and there is a consensus about its efficacy for discontinuing long-term BZD use, especially in terms of improving drug-free outcomes, there have been brought inconclusive results in regard to valproate. On the other hand, studies identified of the new AC are as follows: 2 for gabapentin, 2 for oxcarbazepine, 2 for pregabalin, 1 for tigabine and 2 for topiramate. With the exception of pregabalin, only small studies and cases report have been conducted for most
\end{abstract}

*Corresponding author: Francisco López-Muñoz, Faculty of Health Sciences, Camilo José Cela University, C/ Castillo de Alarcón, 49, Urb. Villafranca del Castillo, 28692 Villanueva de la Cañada, Madrid, Spain, Tel: 34918153131; Fax: 34918609343; E-mail: francisco.lopez.munoz@gmail.com

Citation: Marín-Mayor M, López-Muñoz F, Rubio G (2014) Anticonvulsant Agents for the Management of Benzodiazepine Dependence. J Addict Addictv Disord 1: 003

Received: August 01, 2014; Accepted: September 15, 2014; Published: September 30, 2014

Copyright: (C) 2014 Marín-Mayor M, et al., This is an open-access article distributed under the terms of the Creative Commons Attribution License, which permits unrestricted use, distribution, and reproduction in any medium, provided the original author and source are credited. of the new AC. Pregabalin has demonstrated to be effective in the treatment of BD and BWS, exerting its beneficial action by reducing the severity of withdrawal and anxiety symptoms.

\section{Conclusion}

To date, among AC agents, only carbamazepine and pregabalin can be considered as augmentation alternatives for the treatment of long-term BZD use. Further randomized, double-blind, placebo-controlled studies are necessary to increase the knowledge to support the use of AC for the treatment of BD and BWS.

Keywords: Anticonvulsants; Benzodiazepines; Dependence; Withdrawal syndrome

\section{Introduction}

Benzodiazepines (BZDs) are widely available drugs. In the adult population, the prevalence of daily use of anxiolytic drugs is $4 \%$, and the prevalence of daily use of hypnotics is $1.7 \%$, according to a Spanish survey conducted in 2011 [1]. This is due to their anxiolytic, sedative, and hypnotic properties, and also because they have shown to have a broad-spectrum activity, a rapid onset of action, and a wide therapeutic window compared with other anxiolytic medications [2]. However, chronic use of BZDs has revealed that these drugs can lead to tolerance and dependence [3], as indicated by a BZD Withdrawal Syndrome (BWS) following cessation, characterized by nervousness, irritability, sleep disturbances, dizziness, tremor, diaphoresis and diarrhea, which can be complicated with seizures [4]. In addition, they associate a higher risk of impairments in cognition, memory, attention, reaction time and psychomotor function $[5,6]$. It has been estimated that 30 to $40 \%$ of long-term users of BZDs experience difficulties in withdrawing from these drugs [7]. The risk factors for BZD Dependence (BD) and BWS can be classified as those related with the drug properties (short half-life and high-power BZD), those related to the way how the BZD is used (use of high doses of BZDs, during more than 8 months and a rapid rate of taper) and those related to individual characteristics (previous history of drugs or alcohol dependence or abuse; history of a chronic disease; personality, anxiety or mood disorders; insomnia; females; elderly and a high cultural level) $[2,8]$.

Traditionally, the effective management of BZD discontinuation does not only include pharmacological management, but must address some of the nondrug issues that contribute to withdrawal severity and taper difficulty upon BZD discontinuation [3]. Because minimal interventions and systematic discontinuation programs guided by a physician or psychologist without the augmentation of psychotherapy or pharmacotherapy have demonstrated to be efficacious in a meta-analysis [9], it has been proposed a stepped care approach for discontinuing long-term BZD use. In addition, several adjunctive pharmacological agents have been used to facilitate the tapering of BZD. There is a consensus about gradual rather than abrupt tapering BZDs as a first step for BZD discontinuation $[10,11]$. Other extended traditional strategy has been switching from short half-life BZD to long half-life BZD before gradual taper, with different results as for support $[12,13]$. A great variety of agents have been used as adjuvant medication in BWS with varying degrees of success. Such agents include antidepressants such as mirtazapine [14], paroxetine [15], trazodone [16,17], dothiepin [18] and imipramine 
[19,20]; $\beta$-blocker propranolol [21,22]; a2-agonist clonidine [23]; $5-\mathrm{HT}_{1 \mathrm{~A}}$ partial agonist buspirone [19,20,24]; anxiolytic alpidem [25]; neuroactive steroid progesterone [26]; 5- $\mathrm{HT}_{3}$ antagonist odansetrone [27]; and BZD partial agonist flumazenil [28,29].

Moreover, in the past few years, research has focused in the use of Anticonvulsant (AC) drugs. Classic AC, such as Carbamazepine (CBZ) and Valproate (VPA), especially CBZ, have been widely studied for the treatment of BD and BWS [17,30]. However, because of their drug-to-drug interactions, the need of careful monitoring of serum drug levels, and hepatic and hematologic toxicity, their use is limited [31]. New AC agents offer several advantages over classic AC: they have rapid onset of action, lower toxicity, fewer side effects, and lower interaction with alcohol and other drugs [32]. AC offer several potential advantages in the BZD detoxification process: 1) they decrease the probability of experiencing a seizure, which is a severe complication of BWS [33]; 2) they are efficacious in blocking the "kindling" effect, which refers to the neural sensitization leading to progressive worsening of subsequent withdrawal episodes [34]; 3) they lack abuse liability [35]; 4) they are useful in treating anxiety and affective symptoms that can be evident during protracted BWS [36]; and 5) they lack cognitive and psychomotor impairing effects [37]. The aim of this article is to review the use of AC agents in the management of BWS and BD.

\section{Methods}

MEDLINE and the Cochrane were searched, selecting studies from 1980 until 2014, in which a pharmacological intervention with classic and new AC was made for discontinuing long-term BZD use in both, mono-dependence cases or associated to other Substance Use Disorder (SUD). Major search terms included anticonvulsants, carbamazepine, gabapentin, lamotrigine, levetiracetam, oxcarbazepine, pregabalin, tiagabine, topiramate, valproate, vigabatrine and zonisamide, on one hand, and BD, BWS and BZD-discontinuation, on the other hand. References of identified citations were searched manually to identify papers not located in the in the electronic database search. We independently evaluated each citation for inclusion. All clinical studies, regardless of their design were reviewed.

\section{Results}

\section{Classic anticonvulsants}

Carbamazepine: There is a great body of research involving CBZ. The first study of the successful use of CBZ in BWS was a case series of 3 patients who were treated with Alprazolam (ALP) at dosages higher than $5 \mathrm{mg} /$ day because they suffered from Panic Disorder (PD). CBZ, given in a dosage that ranged from 600 to $800 \mathrm{mg} /$ day for 2 weeks, resulted in a successful reduction of withdrawal symptoms [38]. In a further case series of 9 patients who were taking high doses of BZDs [Chlordiazepoxide (CHL) $2000 \mathrm{mg} /$ day, Clonazepam (CZP) $8 \mathrm{mg} /$ day and ALP $15 \mathrm{mg} /$ day] and who also met criteria for a diagnosis of another SUD, CBZ provided a better tolerated and more rapid discontinuation from BZDs than a taper alone [39]. These initial positive results found in the use of CBZ in the treatment of BWS led to the development of a standardized protocol by Ries [40]. Eighty-five patients, who had BZDs as the primary drugs of abuse, were included in the study. Two slightly different protocols were developed: in the first protocol, a 3-day tapering dose of BZDs was given along with a loading dose of $600 \mathrm{mg} /$ day of CBZ; in the second, CBZ was given in an initial loading dose, although there was no regularly schedule for
BZD discontinuation. Both protocols were rated by the medical staff as better than previous methods of detoxification.

Furthermore, open-label and randomized, double-blinded, placebo-controlled trials have been also published. The first double-blind, placebo-controlled trial was carried out by Rickels et al., in 1990 [41]. Initially, patients who were on BZDs other than Diazepam (DZP), Lorazepam (LZM), or ALP were shifted to a DZP equivalent dosage. Afterwards, patients were pretreated with $\mathrm{CBZ}$ (200-600 mg/day ( $n=13)$ or Placebo (PLA) $(n=45)$, for 2 weeks. For the final 2 weeks, CBZ, still under double-blind conditions, was replaced by PLA. Three and 12-months follow-ups were also conducted. CBZ was associated with a significantly higher percentage of patients that remained BZD-free for at least 5 weeks when compared to PLA ( $91 \%$ vs. $58 \%, \mathrm{p}<0.05)$. These findings were replicated in an open-label study, which included 18 patients (15 females and 3 males) with a $\mathrm{BD}$ [the mean duration of their dependency was 9.05 years and the most frequent BZD used was DZP, followed by LZM and Bromazepam (BRO)], 9 of whom were gradually tapered from BZDs, while the remaining 9 were additionally treated with CBZ (300-600 mg/day) for a further 15 days after BZD discontinuation. Withdrawal, anxiety and depressive symptoms were assessed every 3 days during the study period. This study found that there was a clear trend towards less severe withdrawal symptoms in the CBZ group, reaching significance on days 9-12 after withdrawal. Withdrawal symptoms such as hypersensitivity to sensory stimuli, abnormal perception of movement, depersonalization or derealisation were also less severe in the group treated with CBZ [42]. Concurrently, Schweizer et al., [30] conducted a 12-week, randomized, double-blind, placebo-controlled trial, in which 40 long-term BZD users (21 females and 19 males, with a mean age of 47 years) were randomly assigned to receive treatment with CBZ (200-800 mg/day) or PLA for 10 weeks, together with a BZD tapering of $25 \%$ per week during 4 weeks. The mean duration of the BZD use was 64 months, and the most frequent BZDs used were ALP, LZM and DZP. There were significant differences in the patient's ability to stay off BZDs in favor of the CBZ group at week 5 compared to the PLA group ( $95 \%$ vs. $62 \%, \mathrm{p}<0.03)$, although only trend-level differences were observed between both treatment groups at week 12 ( $74 \%$ vs. $52 \%$, $\mathrm{p}=$ N.S.). In addition, patients receiving CBZ reported a larger reduction in withdrawal severity than patients receiving PLA, but only at a trend level, and only on the daily patient-rated withdrawal checklist. Eleven patients $(28 \%)$ required antidepressant therapy for depression or panic when assessed at 12-weeks follow-up. CBZ resulted an effective adjunctive therapy for BWS, particularly in patients receiving BZDs in daily dosages of $20 \mathrm{mg} / \mathrm{d}$ or greater of DZP equivalents [30]. Finally, Klein et al., [43] examined the possibility that patients with PD are especially vulnerable to ALP withdrawal. After a 2-month open trial of ALP, 36 patients with PD and 35 patients with Generalized Anxiety Disorder (GAD) entered a controlled discontinuation phase, in which CBZ or PLA was added in a randomized, double-blind, placebo-controlled fashion, followed after 1 week by a single-blinded dose reduction of ALP, approximately $25 \%$ every third day. $52 \%$ of the patients were able to discontinue ALP, but only $37 \%$ completed the study, maintaining ALP-free status for 4 weeks. Patients with PD encountered more withdrawal problems than patients with GAD and seemed to benefit more from the addition of CBZ [43].

Only one study has evaluated CBZ (400 mg twice a day) for the treatment of BZD abrupt discontinuation, in 17 patients who had a $\mathrm{BD}$ for more than 0.5 years because of $\mathrm{PD}$ or neurosis. Although 
perception disturbances were noted in 14 patients and most patients showed sleep disturbances, mood alterations or anxiety, epileptic seizures did not occur. CBZ treatment was well tolerated by all patients and caused no severe problems [44].

CBZ has also been used in the treatment of geriatric population. In a case series, it was reported that 4 hospitalized elderly patients (with a mean age of 72.5 years) who suffered from an ALP dependence were successfully withdrawn with CBZ, which was titrated up to 400-500 $\mathrm{mg} /$ day, at the same time that BZD taper occurred over a period of 2-6 days. All the patients were able to reduce their ALP use to no more than $2.5 \mathrm{mg} /$ day and they experienced only mild withdrawal symptoms [45]. Subsequently, a double-blind study was performed to evaluate CBZ for the treatment of BWS in elderly patients. 36 outpatients aged 60 years or over, suffering from GAD and BZD abuse, underwent gradual discontinuation of BZD therapy in two groups, one treated with CBZ and one with PLA. The CBZ-treated group demonstrated a lower incidence of withdrawal $(\mathrm{p}<0.01)$ and anxiety $(\mathrm{p}<0.05)$ symptoms [46].

To conclude, a recent Cochrane systematic review points to the potential value of $\mathrm{CBZ}$ as an effective intervention for BZD gradual taper discontinuation, particularly in patients receiving BZDs at 20 $\mathrm{mg} /$ day or more DZP-equivalent dosages. CBZ showed rather modest benefit in reducing withdrawal severity, although it did significantly improve drug-free outcome [47].

Valproate: Less has been published about the use of VPA in the treatment of BD and BWS. Three cases reported have found VPA to be effective in the treatment of $\mathrm{BD}$ and BWS. The first to report on the use of VPA in BD was Roy-Byrne. It was the case of a 44-year old man diagnosed with Bipolar Disorder and who had been on ALP (2-5 mg/day) for over 3 years. Two initial attempts to discontinue BZDs, one tapering ALP and the other switching to CZP and tapering CZP had been unsuccessful, reporting the patient increased depression, tremulousness and mood swings. In the third attempt of ALP discontinuation, VPA was used, being found to be efficacious in discontinuing BZDs and maintaining the patient BZD-free 6 months after VPA was initiated [48]. Apelt and Emrich [49], a short time later, published a case series of 4 inpatients (aged 24-44 years) diagnosed with BD (BZD use ranged from 1 to 18 years), in which symptoms of protracted BZD withdrawal, including psychosis, anxiety, panic, vomiting, insomnia, ataxia, and paresthesia that appeared between 11 and 21 days after BZD tapering, were successfully treated with VPA [49]. Finally, McElroy et al., [50] reported the case of a 23-year-old male with a severe treatment-resistant PD complicated by CZP-induced interdose rebound and withdrawal symptoms. The patient had initially been treated with DZP (90 mg/day), but an attempted taper of DZP resulted in an abrupt increase of daily panic and generalized anxiety $(55 \mathrm{mg} /$ day). CZP was substituted over a 3-day period with a final dose of $12 \mathrm{mg}$ /day over four doses. However, the patient continued to complain of generalized anxiety and he experienced a worsening of symptoms when CZP was attempted to be reduced. For this reason VPA was added and increased to a total dose of $2250 \mathrm{mg} /$ day. CZP was then discontinued without anxiety or withdrawal symptoms [50]. However, in the only randomized, double-blind, placebo-controlled study, in which 78 patients, taking a mean dose of $19 \mathrm{mg} /$ day of DZP (or its equivalent), were stabilized for several weeks on their BZD (16 DZP, 25 LZM and 37 ALP) and then pretreated for 1-2 weeks with Trazodone (TRA) (100-500 mg/day) $(\mathrm{n}=41)$, VPA $(500-2500$ $\mathrm{mg} /$ day $)(\mathrm{n}=19)$ or PLA $(\mathrm{n}=18)$, before being tapered at $25 \%$ per week, failed to find any significant effect on withdrawal severity, although more patients remained BZD-free in the VPA group compared to patients in the TRA and PLA groups $(79 \%$ vs. $67 \%$ vs. $31 \%$, respectively, $\mathrm{p}<0.03)$ at week 5 . Taper success did not remain significant at 12-week follow-up. Major adverse events for VPA were diarrhea, nausea and headache [17].

\section{New anticonvulsants}

Gabapentin: Gabapentin (GBP), 1-(aminomethyl) cyclohexaneacetic acid, is a second generation anticonvulsant, which has shown to bind with high affinity to $\alpha 2 \delta 1$-subunit of voltage-gated calcium channels [51]. Through this mechanism, GBP can cause a decrease in calcium influx in presynaptic nerve terminals and inhibit the release of excitatory aminoacids such as Glutamate (GLU) [52], Noradrenaline (NA), Dopamine (DA) and Serotonin (5-HT) [53]. GBP lacks drug-to-drug interactions due to absence of protein binding and hepatic metabolism, so it is not affected by liver dysfunction. In addition, it has a renal excretion as an unchanged drug. It also lacks cognitive impairment and lacks abuse potential, not requiring blood monitoring [54].

To date, only one case report [55] and an open-label study [56] have been published in regard to the use of GBP in the treatment of BD. Crockford et al., were the first to report the case of a 49 year-old woman, with a 7-year history of continuous intake of 12 to $15 \mathrm{mg}$ of ALP per day, who was successfully detoxified using GBP (600 $\mathrm{mg}$ /day), after having failed a tapering approach with CZP $2 \mathrm{mg}$ twice daily. She reported a rapid reduction of symptoms of anxiety, tremor and affective lability, and 2 months later she remained ALP-free [55]. At the same time, a Spanish group communicated in a Spanish Congress the results of a 3-month, open-label, prospective study which included 17 patients (53\% females and 47\% males), who were under an Opiate Substitution Treatment with Methadone and met DSM-IV criteria for BZD abuse or dependence. GBP was given in a range of dosage from 1200 to $4800 \mathrm{mg}$ /day (mean dosage 2588 $\mathrm{mg} /$ day) and BZDs were gradually tapered for 21 days. The $60 \%$ of the patients remained BZD-free at the end of the study. In addition, there was a reduction in withdrawal and anxiety symptoms, as well as in perceived stress, with an improvement in global functioning. GBP was well tolerated in general, with mild and transient side effects such as dizziness and dry mouth, which progressively disappeared [56].

Oxcarbazepine: Oxcarbazepine (OXC), the 10-keto-analogue of $\mathrm{CBZ}$, is a new generation anticonvulsant whose mechanism of action is thought to be by a double pathway: 1) blocking voltage-sensitive sodium channels, thereby stabilizing neural membranes, inhibiting repetitive neuronal firing, and reducing synaptic impulse activity; and 2) reducing high voltage-activated calcium currents in striatal and cortical neurons, thus reducing glutamatergic transmission at corticostriatal synapses [57]. In contrast to CBZ, OXC's major route of elimination is through renal excretion and not through the cytochrome $\mathrm{P} 450$ oxidase system, which implies an enhanced tolerability, lower drug-interaction potential and reduced liver toxicity than CBZ. Its steady-state is reached within 2-3 days (half-life 8-10 hours) which is even earlier than CBZ.

Until now, only a German group has published two case series studies of OXC for BZD detoxification. In the first study they reported the cases of 3 patients (one male and one with comorbid alcohol dependence) [58]. In the later study, 10 patients (2 males and 8 females) who fulfilled DSM-IV and ICD-10 criteria of BD, and who were taking BZDs in an equivalence-dose of DZP of 20-300 mg/day, 
Citation: Marin-Mayor M, López-Muñoz F, Rubio G (2014) Anticonvulsant Agents for the Management of Benzodiazepine Dependence. J Addict Addictv Disord 1: 003 .

\begin{tabular}{|c|c|c|c|}
\hline $\begin{array}{l}\text { Author; } \\
\text { No. of patients }\end{array}$ & $\begin{array}{l}\text { Design; } \\
\text { Duration; Intervention }\end{array}$ & Outcomes & Results \\
\hline \multicolumn{4}{|l|}{ CARBAMAZEPINE } \\
\hline Klein et al., $\mathrm{N}=3$ & $\begin{array}{l}\text { CS } 2 \text { weeks ALP withdrawal }(>5 \mathrm{mg} / \mathrm{d}) \text { CBZ }(600-800 \\
\mathrm{mg} / \mathrm{d})\end{array}$ & Reduction of withdrawal symptoms & $\begin{array}{l}\text { CBZ was associated with a successful } \\
\text { reduction of withdrawal symptoms }\end{array}$ \\
\hline Ries et al., $\mathrm{N}=9$ & $\begin{array}{l}\text { CS BD (CHL } 2000 \mathrm{mg} / \mathrm{d}, \text { CZP } 8 \mathrm{mg} / \mathrm{d} \text { and ALP } 15 \\
\text { mg/d) + PSUD CZP + BZD tapering }\end{array}$ & Discontinuation of BZD intake & $\begin{array}{l}\text { Discontinuation of BZD was well tolerat- } \\
\text { ed and rapid }\end{array}$ \\
\hline Rickels et al., $\mathrm{N}=58$ & $\begin{array}{l}\text { DB, PC trial } 2-4 \text { weeks BZD stabilization period } \\
+2 \text { weeks of treatment period }+2 \text { weeks of PLA } \\
\text { treatment }+12 \text {-months follow-up CBZ }(200-600 \mathrm{mg} / \mathrm{d}) \\
(n=13) \text { vs PLA }(n=45)\end{array}$ & $\begin{array}{l}\text { Ability of the patients to remain BZD free for } \\
\text { at least } 5 \text { weeks }\end{array}$ & $\begin{array}{l}\text { CBZ caused a significantly higher } \% \\
\text { of patients who remained BZD-free com- } \\
\text { pared to PLA }(p<0.05)\end{array}$ \\
\hline Ries et al., $\mathrm{N}=85$ & $\begin{array}{l}2 \text { treatment protocols: } 3 \text { days } \\
\text { Protocol 1: CBZ }(600 \mathrm{mg} / \mathrm{d})+\text { BZD tapering Protocol } \\
\text { 2: CBZ }(600 \mathrm{mg} / \mathrm{d}) \text { without BZD tapering }\end{array}$ & $\begin{array}{l}\text { Staff ratings compared to previous detoxifica- } \\
\text { tion methods }\end{array}$ & $\begin{array}{l}\text { CBZ was rated as better than previous } \\
\text { detoxification methods }\end{array}$ \\
\hline $\begin{array}{l}\text { García-Borreguero et al., } \\
N=18\end{array}$ & $\begin{array}{l}\text { R, C study } 15 \text { days BD (mean duration } 9.05 \text { years. } \\
\text { DZP, LZM and BRO the most frequently BZD used) } \\
\text { Gradual BZD tapering ( } n=9) \text { vs adding CBZ (300-600 } \\
\text { mg/d) }(n=9)\end{array}$ & $\begin{array}{l}\text { Withdrawal (BWSQ-2), anxiety (SAS) and } \\
\text { depressive (SDS) symptoms }\end{array}$ & $\begin{array}{l}\text { CBZ was associated with a trend } \\
\text { towards lesser severe withdrawal } \\
\text { symptoms }\end{array}$ \\
\hline Swantek et al., $N=4$ & $\begin{array}{l}\text { CS } 2-6 \text { days } \\
\text { Elderly patients ALP dependence } \\
\text { CBZ }(400-500 \mathrm{mg} / \mathrm{d})+\text { BZD tapering }\end{array}$ & $\begin{array}{l}\text { Reduction of ALP use } \\
\text { Intensity of withdrawal symptoms }\end{array}$ & $\begin{array}{l}\text { All patients were able to reduce the } \\
\text { dose of ALP used (no more than } 2.5 \\
\mathrm{mg} / \mathrm{d} \text { ) } \\
\text { Patients experienced only mild with- } \\
\text { drawal symptoms }\end{array}$ \\
\hline Schweizer et al., $\mathrm{N}=40$ & $\begin{array}{l}\text { R, DB, PC ALP, LZM or DZP dependence } \\
\text { CBZ (200-800 mg/d) + BZD tapering } 25 \% \text { per week }\end{array}$ & $\begin{array}{l}\text { Achievement of BZD-free Intensity of with- } \\
\text { drawal symptoms }\end{array}$ & $\begin{array}{l}\text { More patients in the CBZ group } \\
\text { remained BZD-free and there was a } \\
\text { greater reduction in withdrawal severity } \\
\text { in this group }\end{array}$ \\
\hline Di Constanzo et al., $\mathrm{N}=36$ & $\begin{array}{l}\text { DB, PC Elderly patients with GAD + BZD abuse } \\
\text { CBZ + Gradual BZD tapering }\end{array}$ & $\begin{array}{l}\text { Withdrawal (PWCL, HSCL) and anxiety } \\
\text { (HARS) symptoms }\end{array}$ & $\begin{array}{l}\text { CBZ-treated group demonstrated a } \\
\text { lower incidence of withdrawal }(p<0.01) \\
\text { and anxiety }(p<0.05) \text { symptoms }\end{array}$ \\
\hline Klein et al., $N=71$ & $\begin{array}{l}\text { 2-month OL of ALP + Discontinuation phase } R, D B \text {, } \\
P C+1 \text {-week SB dose reduction of ALP } \\
\text { PD }(n=36) \text { and GAD }(n=35) \\
\text { ALP discontinuation } \\
\text { CBZ vs PLA with BZD tapering } 25 \% \text { each } 3 \text { days }\end{array}$ & $\begin{array}{l}\text { Achievement of BZD-free Withdrawal } \\
\text { symptoms }\end{array}$ & $\begin{array}{l}52 \% \text { of the patients were able to discon- } \\
\text { tinue ALP, but only } 37 \% \text { completed the } \\
\text { study, maintaining ALP-free status for } 4 \\
\text { weeks. Patients with PD encountered } \\
\text { more withdrawal problems than patients } \\
\text { with GAD and seemed to benefit more } \\
\text { from the addition of CBZ }\end{array}$ \\
\hline Kaendler et al., $\mathrm{N}=17$ & $\begin{array}{l}\text { OL BZD use for at least } 0.5 \text { years Abrupt withdrawal + } \\
\text { CBZ ( } 400 \mathrm{mg} \text { twice a day) }\end{array}$ & $\begin{array}{l}\text { Anxiety, mood alterations, perception } \\
\text { disturbances, neurological symptoms and } \\
\text { vegetative signs }\end{array}$ & $\begin{array}{l}\text { Perception disturbances were noted in } \\
14 \text { patients. Most patients showed sleep } \\
\text { disturbances, mood alterations and } \\
\text { anxiety. However, epileptic seizures did } \\
\text { not occur }\end{array}$ \\
\hline \multicolumn{4}{|l|}{ VALPROATE } \\
\hline Roy-Byrne et al., $\mathrm{N}=1$ & $\begin{array}{l}\text { CR BD + ALP dependence }(2-5 \mathrm{mg} / \mathrm{d}) \mathrm{VPA}+\mathrm{BZD} \\
\text { tapering }\end{array}$ & $\begin{array}{l}\text { Achievement of BZD free Withdrawal } \\
\text { symptoms }\end{array}$ & $\begin{array}{l}\text { VPA was efficacious in discontinuing } \\
\text { BZDs and maintaining the patient BZD- } \\
\text { free after } 6 \text { months }\end{array}$ \\
\hline Apelt et al., $N=4$ & $\begin{array}{l}\text { CS BRO, DZP, LZM and CHL dependence } \\
\text { VPA ( } 1200 \mathrm{mg} / \mathrm{d})\end{array}$ & $\begin{array}{l}\text { Efficacy in treating Protracted BZD Withdraw- } \\
\text { al Symptoms }\end{array}$ & $\begin{array}{l}\text { Protracted BZD Withdrawal Symptoms } \\
\text { ended when VAL was initiated }\end{array}$ \\
\hline Mc Elroy et al., $\mathrm{N}=1$ & $\begin{array}{l}\text { CR } \\
\text { CZP withdrawal } \\
\text { VPA (up to } 2250 \mathrm{mg} / \mathrm{d} \text { ) + CZP tapering }\end{array}$ & $\begin{array}{l}\text { Succeed in CZP discontinuation without } \\
\text { withdrawal symptoms }\end{array}$ & $\begin{array}{l}\text { CZP was discontinued without withdraw- } \\
\text { al and anxiety symptoms }\end{array}$ \\
\hline Rickels et al., $N=78$ & $\begin{array}{l}R, D B, P C 12 \text { weeks BD (mean dose of } 19 \mathrm{mg} / \mathrm{d} \text { DZP } \\
\text { or its equivalent; BZD used: } 16 \text { DZP, } 25 \text { LZM and } 37 \\
\text { ALP) VPA }(n=19)(500-2500 \mathrm{mg} / \mathrm{d}) \text { vs TRA }(100-500 \\
\text { mg/d) }(n=41) \text { vs PLA }(n=18)+\text { BZD tapering } 25 \% \\
\text { per week }\end{array}$ & $\begin{array}{l}\text { Peak severity during taper (PWCL) BZD } \\
\text { status 5-weeks post-taper defined as off od } \\
\text { on BZD }\end{array}$ & $\begin{array}{l}\text { Peak PWCL change from baseline to } \\
\text { peak severity was } 16.4 \text { for TRA, } 18.04 \\
\text { for and } 18.24 \text { placebo ( } F=0.10 ; N S) \text {. } \\
\text { More patients remained BZD-free in the } \\
\text { VPA group compared to patients in the } \\
\text { TRA and PLA groups ( } 79 \% \text { vs } 67 \% \text { vs } \\
31 \% \text {, respectively, } p<0.03 \text { ) at week } 5 \text {. }\end{array}$ \\
\hline
\end{tabular}

Table 1: Studies in which classic AC have been assessed for the discontinuation of long-term BZD-use.

ALP: Alprazolam; BD: Benzodiazepine Dependence; BRO: Bromazepam; BWS: Benzodiazepine Withdrawal Syndrome; BWSQ-2: Benzodiazepine Withdrawal Symptom Questionnaire; BZD: Benzodiazepine; C: Controlled; CBZ: Carbamazepine; CHL: Chlordiazepoxide; CS: Case Series; CZP: Clonazepam; DB: Double-Blind; DZP: Diazepam; GAD: Generalized Anxiety Disorder; HSCL: Hopkins Symptom Check List; LZM: Lorazepam; OL: Open-Label; PC: Placebo-Controlled; PD: Panic Disorder; PLA: Placebo; PWCL: Physician Withdrawal Check List; R: Randomized; SAS: Self-Rating Anxiety Scale; SB: Single-Blind; SDS: Self-Rating Depression Scale; TRA: Trazodone; VPA: Valproate 
for at least 4 weeks, were included. The entire inpatient withdrawal lasted 11 to 21 days and OXC was maintained for a further 6-month period [59]. In both studies, DZP equivalence-dose taken before admission was calculated in each case and all patients were then withdrawn from DZP, so that for Low-dose-dependence (up to $30 \mathrm{mg} /$ day) DZP was reduced by $5 \mathrm{mg}$ every 2 days, whereas for High-dose-dependence (more than $30 \mathrm{mg} /$ day) DZP was reduced by $25 \%$ every 2 days to approximately $30 \mathrm{mg} /$ day, after which they proceeded as with Low-dose-dependence. At the same time, OXC was titrated following the next scheme: $150 \mathrm{mg} /$ day for the first 4 days; $150 \mathrm{mg}$ every two days up to a dosage of $1200 \mathrm{mg} /$ day, from day 5 to day 12. It was found that all patients detoxified with OXC completed the withdrawal successfully without withdrawal symptoms, remaining abstinent from BZD after discharge. In addition, OXC was well tolerated.

Pregabalin: Pregabalin (PGN), (S)-3-(aminomethyl)-5-methylhexanoic acid, is an antiepileptic drug of the third generation, and a structural analog of GABA acid, which binds selectively the $\alpha 2 \delta$ subunit of voltage-gated calcium channels and reduces the influx of calcium, subsequently reducing the exocytosis of synaptic vesicles in the synaptic site [60], as a result of which it acts as a presynaptic modulator of the excessive release in hyperexcited neurons of excitatory neurotransmitters including GLU, NA and substance $P$ [61]. PGN's pharmacokinetic profile is linear with rapid oral absorption and a bioavailability of at least $90 \%$. Peak plasma concentrations occur between 0.7 and 1.3 hours. It has no potential binding to plasma proteins. It lacks of metabolites. Its elimination half-life is 6 hours and steady-state is achieved within 24-48 hours, being renal excretion essentially the only pathway for its systemic elimination. Inview of dose-dependentadverse reactions and since PGN is eliminated primarily by renal excretion, daily dose of PGN should be adjusted based on renal function. PGN does not inhibit the major cytochrome P450 enzymes and therefore it shows no drug-to-drug interaction [62].

To date, the greater body of research in the treatment of BD and BWS involves PGN. The first group to report on the effectiveness of PGN for treating BWS was Biermann et al., [63]. They reported a case of a 39 year-old patient diagnosed with Social Phobia (SP) and GAD, who was also suffering from a depressive episode with sleep disturbances and BD (he had been using ALP $5 \mathrm{mg}$ die for 4 years). PGN (up to $300 \mathrm{mg} /$ day) was given with the aim of treating social and generalized anxiety, as well as lessening symptoms of BZD withdrawal. ALP was switched to DZP, which was tapered until cessation. However, 12 days after terminating DZP treatment the patient reported undesirable side effects due to PGN (facial hypoesthesia and tongue swelling), which motivated the discontinuation of PGN treatment. This resulted in a re-emergence of symptoms such as generalized anxiety, sleep dysfunction, agitation, tremor, headache, paresthesia concerning temperature, freezing and mild shivering, muscle pain, gastrointestinal irritations and mood instability, which were attributed as BZD withdrawal symptoms, concluding the authors that PGN could be useful for treating BZD withdrawal.

Subsequently, a Greek group [37,64-67] reported a small series of four female patients with a long history of uninterrupted high-dosage $\mathrm{BD}$ (ranging from 5 to 27 years), who were incrementally switched to PGN at doses that ranged from 225 to $600 \mathrm{mg} /$ day (mean dosage 390 $\mathrm{mg} /$ day) within 3-7 weeks (mean duration of substitution process 5 weeks). In this case, PGN was found to be effective in terms of reducing anxiety levels by $60-80 \%$ [64]. These encouraging findings motivated the same group to carry out an open-label clinical study in which 15 patients (12 females and 3 males) with chronic BD (mean duration of BZD use of 13.23 years) and a concomitant affective disorder, mainly major depressive disorder or dysthymic disorder, were switched from their previous BZD to PGN in a dosage that ranged from 225 to 900 $\mathrm{mg}$ /day (mean dosage $465 \mathrm{mg} /$ day) in a substitution process that lasted from 2 to 14 weeks (mean duration 5.53 weeks). On completion of the transition process, anxiety and depressive levels dropped by $53.2 \%$ and $51.5 \%$, respectively. PGN's side effects were transient and included dizziness, fatigue, sedation, leg cramps and dysarthria [65]. In the most recent study designed by this group, they went a step forward, exploring the effects of PGN in the neurocognitive performance of 14 female patients with long-term BZD use (the mean duration of the BD was 15.43 years, range 3-30 years), who had a comorbid diagnosis of a dysthymic disorder and/or a personality disorder of the Cluster B [37]. The BZDs taken by these patients were as follows: BRO at $9 \mathrm{mg} / \mathrm{d}$ ( 5 patients), ALP at 1-6 mg/day (6 patients) and LZM at 4-7 mg (3 patients). PGN was incrementally substituted for BZD in a dosage that ranged from 150 to $900 \mathrm{mg} /$ day (mean dosage $509 \mathrm{mg} /$ day), lasting the substitution process 3.5 weeks (range from 3 to 7 weeks). Patients improved substantially in overall cognitive functioning from baseline to 2-month follow-up after the completion of the transition from BZD to PGN ( $\mathrm{p}=0.017)$. This improvement was attributable mainly to their improvement in orientation $(\mathrm{p}<0.03)$, especially orientation in time $(\mathrm{p}<0.03)$, and to a much lesser extent to an improvement in memory recall ( $\mathrm{p}=\mathrm{N}$.S.). In addition, they improved in measures of psychomotor speed $(\mathrm{p}=0.041)$, visuospatial memory $(\mathrm{p}=0.02)$ and learning $(\mathrm{p}=0.011)$, although they failed to improve in tests of attentional flexibility $(\mathrm{p}=\mathrm{N} . \mathrm{S}$.). The authors concluded that the possible adverse cognitive effects of PGN-use in the treatment of long-term $\mathrm{BD}$ are less severe than those of prolonged long-term BZD use.

Concurrently, a Spanish group has also carried out a multicenter, 12-week, prospective, uncontrolled and observational study, which included 282 patients diagnosed with BD regardless of if they met criteria for other SUD. The most frequent BZD abused was ALP $(n=177,62.8 \%)$, the mean duration of the BD was 2 years, and the average number of previous detoxification attempts was 0.7. PGN was titrated from day 1 with a starting dose of $75 \mathrm{mg}$, which was up-titrated at $75 \mathrm{mg}$ intervals on a weekly basis to $300 \mathrm{mg}$ after 4 weeks. At the same time, BZDs were tapered by $25 \%$ at weekly intervals until completely withdrawn after 4 weeks. PGN's mean dose was $315 \mathrm{mg} /$ day (ranging from 25 to $450 \mathrm{mg}$ /day). It was found that the success global rate defined as the achievement of a BZD-free status at week 12 was $52 \%$ ( $58 \%$ for women and $46 \%$ for men) ( $\mathrm{p}=0.0516$ ), although it increased up to $70 \%$ when only patients who completed the 12-week follow-up $(n=211)$ were considered. The proportion of patients who were BZD-free at the end of the study did not differ according to the BZD abused or the presence of other SUD. In addition, significant and clinically relevant improvements in withdrawal $(\mathrm{p}<0.0001)$ and anxiety $(\mathrm{p}<0.0001)$ symptoms, as well as patient's global functioning were observed associated to PGN treatment. The authors concluded that because the improvement in anxiety symptoms in the study, especially the physic symptoms, was clinically relevant as early as the first week, this rapid onset of the anxiolytic effect of PGN may play an essential role in the subsequent success of BZD withdrawal $[36,68]$. In a secondary analysis of this 
study, the authors found that PGN was also effective in improving subjective sleep quality in this population group, measured with the Medical Outcomes Study Sleep Scale (MOS Sleep Scale). Its mean score was reduced by $55 \%$ at the end of the study $(\mathrm{p}<0.001)$, reaching clinical relevancy as early as from week 2 . The effect of PGN on overall sleep problems was similar regardless of the BZD abused. The authors concluded that the mechanism that could be underlying the improvement in sleep measures associated to PGN could be related to its efficacy in improving anxiety symptoms [69]. PGN's tolerability was considered excellent or good in most subjects.

Finally, the results previously described above have been confirmed in a recent 12-week, double-blind, placebo-controlled trial which included 106 outpatients with a lifetime diagnose of GAD who had been treated with BZD for 8-52 weeks. Patients were first stabilized for 2-4 weeks with ALP in the range of 1-4 mg/day and then randomized to treatment with either PGN (300-600 mg/day) or PLA while undergoing a gradual BZD taper at a rate of $25 \%$ per week, followed by a 6 week BZD-free phase during which they continued double-blind study treatment. Although the proportion of patients who remained BZD-free was higher in the group taking PGN than PLA (51.4\% vs. $37.0 \%$, respectively) this difference did not reach statistical significance. However, among the subgroup of study completers, $95.5 \%$ of patients receiving PGN were relapse-free at the end of the study, compared with $80 \%$ receiving PLA. In addition, treatment with PGN was associated with a significant reduction in anxiety $(\mathrm{p}<0.001)$ and withdrawal $(\mathrm{p}=0.012)$ symptoms, with an improvement in cognitive and psychomotor profile. PGN was well tolerated, and the only two adverse events reported were dizziness and paresthesias [70].

Tiagabine: Tiagabine (TGB) is a selective GABA Transporter 1 (GAT1) reuptake inhibitor, which has anxiolytic properties through the facilitation of GABAergic neurotransmission [71,72] and also acts through an indirect GABAergic inhibition on the DA-driven reward system of the brain [73], mechanisms which could contribute to its efficacy in the treatment of BD.

To date, only one case report has been published in regard to the use of TGB in the discontinuation of long-term BZD use. It was the case of a 68-year-old female with a 15-year history of GAD and BD. For the last 5 years she was abusing BZDs, taking BRO at a dosage of $75 \mathrm{mg} /$ day. TGB was incrementally substituted up to $15 \mathrm{mg} /$ day for BRO within one week, each day replacing $10 \mathrm{mg}$ of BRO with $2 \mathrm{mg}$ of TGB. TGB was found to be effective in terms of reducing anxiety symptoms, measured by the Halmilton Anxiety Rating Scale (HARS), which score was reduced by $44 \%$ at the end of the treatment period. It was also well tolerated and the patient only described transient side-effects such as dizziness, headache and sedation, which subsided 10 days [74].

Topiramate: Topiramate (TPM) is a sulfamate-substituted analog of fructose-1,6-diphosphate, whose efficacy in the treatment of SUD is thought to be through three mechanisms of action. Firstly, TPM facilitates Gamma-Aminobutyric Acid (GABA) transmission by binding to a non-BZD site on GABA-A receptors [75] and inhibits glutamatergic transmission at ionotropic Alpha-amino-3-hydroxi-5-Methilisoxazole-Propionic Acid (AMPA) and kainite glutamate receptors [76], which mediate voltage-dependent sodium [77] and L-type calcium currents [78]. Secondarily to these actions, TPM neuro-stabilizes and downstream reduces DA release in the corticomesolimbic system, which is involved in the mechanism of reward and reinforcement. In addition, TPM's blockade of
AMPA-type GLU receptors in the nucleus paragigantocellularis appears to inhibit noradrenergic neuron in the locus coeruleus, the activation of which plays an essential role in producing autonomic symptoms of withdrawal states. Finally, because of its weak inhibition of carbonic anhydrase, it could contribute to an anticonvulsant effect, a potentially important property in the treatment of withdrawal syndromes [79]. It has a specific pharmacokinetic profile, which is characterized by: 1) a biovariability of at least $80 \%$; 2) it reaches its maximum concentration between 1.3-1.7 hours post-ingestion; 3 ) it has a half-life of 19-23 hours; 4) it reaches steady-state plasma concentration in about 4 days; 5) it has low binding potential to proteins; 6) less than $20 \%$ of it undergoes metabolism to inactive metabolites; 7) up to $80 \%$ unchanged excretion in the urine; and 9) has little drug-to-drug interactions [32].

Until now, there only exist two published case reports of TPM in the treatment of BD and BWS in the scientific literature. In 2003, Cheseaux et al., [80] described the case of a 41 year-old man with a very severe $\mathrm{BD}$, who had been also using cannabis since the age of 13 , and opiates and cocaine since the age of 20 . He reported an intranasal consumption of $90 \mathrm{mg} /$ day of Midazolam (MID), which had lasted for approximately 7 years. He was rapidly detoxified using TPM, starting with $300 \mathrm{mg}$ on day 1 , followed by $500 \mathrm{mg}$ on days $2-3$, with a taper out until day 9. The patient completed a successful BZD withdrawal, only describing insomnia and nausea as withdrawal symptoms. In addition, during the 2 subsequent months after being discharged from the inpatient program, he remained BZD-free [80]. More recently, Michopoulos et al., [81] have reported the case of a 44 year old woman who was diagnosed with Recurrent Major Depressive Disorder, Subthreshold Anxiety Disorder and histrionic traits, and a co-occurring ALP dependence, using 5-6 mg/day of ALP for 7 years, with multiple failed trials of long-acting BZDs, lamotrigine and Serotonin Selective Reuptake Inhibitors (SSRI). The patient was able to reduce ALP use to $1.5 \mathrm{mg} /$ day at 6 months without experiencing withdrawal symptoms, while treated with TPM, following a tapering method which consisted in adding $25 \mathrm{mg}$ /day of TPM, reaching a dosage of $200 \mathrm{mg} /$ day, while ALP was simultaneously reduced by $0.5 \mathrm{mg} /$ day every 10 days [81].

\section{Discussion}

Although multiple pharmacological agents have been investigated as adjunctive treatments for BWS and $\mathrm{BD}$, there is only enough evidence for a few of them as to be considered efficacious for discontinuing log-term BZD use. One of these successful groups has been the one constituted by the AC agents.

There are several potential advantages when using AC in the treatment of $\mathrm{BD}$ and BWS: 1) they reduce the likelihood of experiencing a seizure, symptom that is considered as a severe complication of BWS [33]; 2) they are effective in blocking the "kindling" effect, which refers to the progressive worsening of subsequent withdrawal episodes due to neural sensitization [34];3) they are absent of abuse liability and dependence [35]; 4) they are efficacious in treating anxiety and affective symptoms that can accompany protracted BWS [36]; and 5) they lack cognitive and psychomotor impairing effects $[37,70]$.

In regard to classical $\mathrm{AC}$, on one hand, $\mathrm{CBZ}$ has been considered the only effective intervention together with gradual rather than abrupt withdrawal of BZD in a systematic Cochrane Database review [47]. Although it showed modest benefits in reducing withdrawal severity, it did significantly improve drug-free outcome. CBZ was 
Citation: Marin-Mayor M, López-Muñoz F, Rubio G (2014) Anticonvulsant Agents for the Management of Benzodiazepine Dependence. J Addict Addictv Disord 1: 003 .

- Page 7 of $10 \bullet$

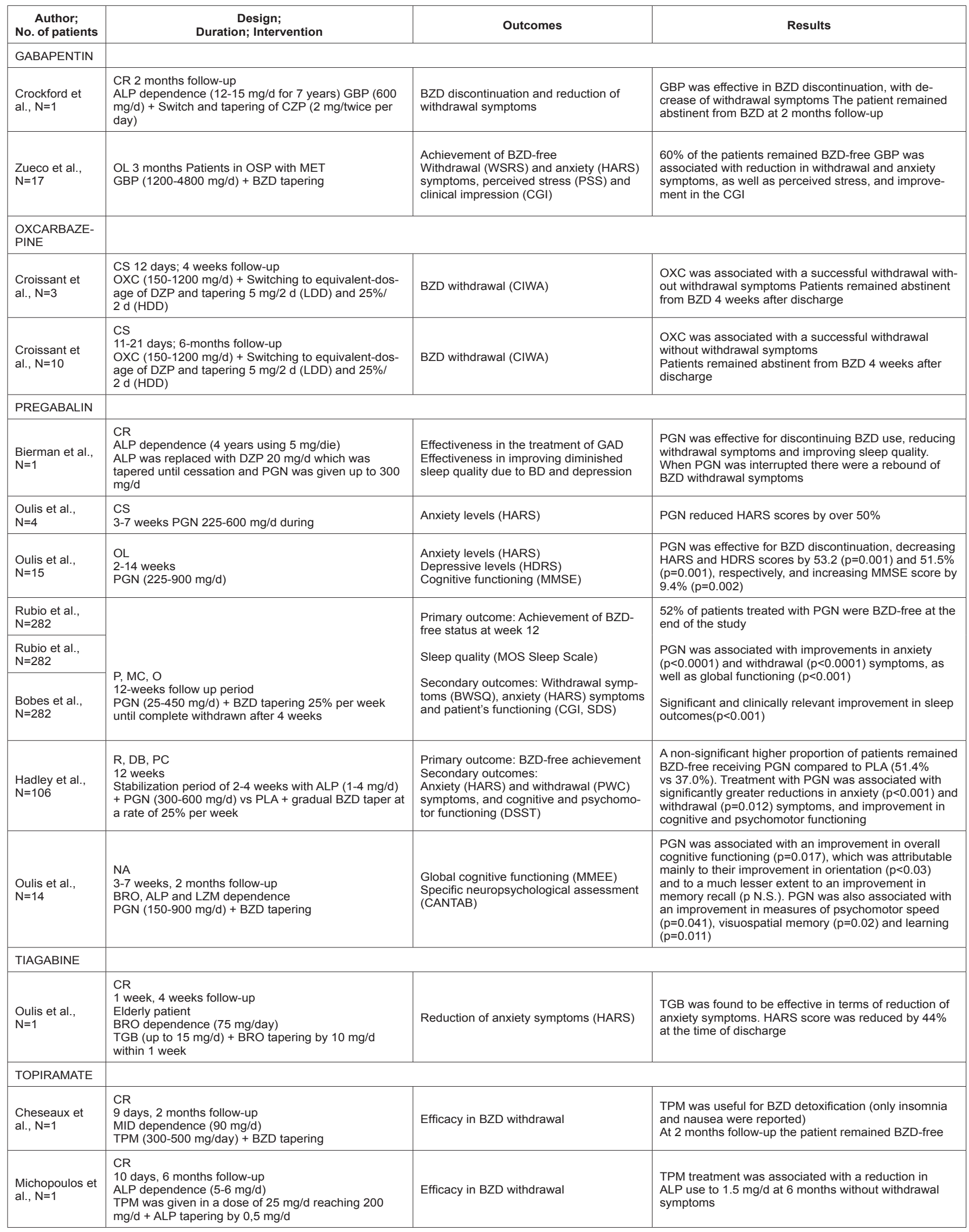

Table 2: Studies in which new AC have been assessed for the discontinuation of long-term BZD-use. 
ALP: Alprazolam; BRO: Bromazepam; BWSQ: Benzodiazepine Withdrawal Symptom Questionnaire; BZD: Benzodiazepines; CANTAB: Cambridge Neuropsychological Test Automated; CGI: Clinical Global Impression Clinical Scale; CIWA: Revised Clinical Institute Withdrawal Assessment for Alcohol Scale; CR: Case Report; CS: Case Series; CZP: Clonazepam; DB: Double-Blinded; DSST: Digit Symbol Substitution Test; DZP: Diazepam; GBP: Gabapentin; HARS: Hamilton Anxiety Rating Scale; HADR: Hamilton Depression Rating Scale; HDD: High-Dose-Dependence; LDD: Low-Dose-Dependence; LZM: Lorazepam; MC: Multicenter; MET: Methadone; MID: Midazolam; MMEE: Mini-Mental State Examination; MOS: Medical Outcomes Study Sleep Scale; NA: Neuropsychological Assessment; O: Observational; OL: Open-Label; OST: Opiate Substitution Program; OXC: Oxcarbazepine; P: Prospective; PC: Placebo-Controlled; PGN: Pregabalin; PLA: Placebo; PSS: Perceived Stress Scale; PWC: Physician Withdrawal Checklist; R: Randomized; SDS: Sheehan Disability Scale; TGB: Tiagabine; TPM: Topiramate; WSRS: Withdrawal Symptoms Rating Scale

considered to be effective particularly in patients receiving BZDs at 20 $\mathrm{mg} /$ day or more DZP-equivalent dosages. These findings are partially supported by the results of a meta-analysis which included 29 articles and in which augmentation with CBZ as a BZD discontinuation strategy was considered as successful, although the effect of CBZ only showed a trend towards statistical significance $(p=0.06)$ [9]. On the other hand, in spite of initial cases report showing promising results in regard with the use of VPA in the treatment of $\mathrm{BD}$ and $\mathrm{BWS}$, the only randomized, double-blind, placebo-controlled trial conducted to date, failed to demonstrate its efficacy in reducing the severity of BZD withdrawal symptoms, and only succeed in terms of achievement rates of BZD-free at the endpoint of the study [17].

Nevertheless, CBZ and VPA's use is frequently avoided in the clinical practice because they are susceptible to cause enzymatic induction (CBZ) or inhibition (VPA), resulting in drug-to-drug interactions with a decrease or increase, respectively, in the serum concentrations of other drugs, which requires careful monitoring. In addition, they are associated with hepatic and hematologic toxicity, and undesirable side effects such as dizziness, diplopia, ataxia, allergic skin reactions, pruritus, vomits and nausea, as well as changes in the electrolytes, especially hyponatremia, in the case of CBZ, and gastrointestinal disturbances, confusion, tremor, hepatic or central encephalopathy and pancreatitis in the case of VPA $[31,82,83]$. Newer AC offer the advantage of having a rapid onset of action, lower toxicity, fewer side effects, and lower interaction with alcohol and other drugs [32].

Current available data only supports the use of the new AC PGN in the treatment of $\mathrm{BD}$ and BWS. Two robust studies, a 12-week, prospective, observational, multicenter study including 282 patients $[36,68]$, and a 12-week, randomized, double-blind, placebo-controlled trial including 106 patients [70], have found that PGN is effective in reducing withdrawal and anxiety symptoms, as well as sleep parameters, cognitive and psychomotor functioning, and to a lesser extent it helps in achieving the maintenance of BZD abstinence. According to the studies reviewed, PGN's required dosage range in BD seems to be much higher (by more than 70\%) than in AUD. PGN might exert its therapeutic action through the reduction of anxiety symptoms $[36,70]$. Although potential tolerance and abuse has been described associated to PGN treatment, PGN's potential for physical and psychological dependence is much lower than that of BZDs [66]. PGN's most frequent, though mostly transient and dose-related, side effects are dizziness, somnolence, blurred vision, dry mouth, weight gain, peripheral edema and attention and concentration disturbances [66].

Although GBP and TPM, have been found to be effective for the treatment of AUD [32,82-84], only anecdotal cases report and small studies have been published to date in regard to their use in $\mathrm{BD}$ and BWS $[55,56,80,81]$, and further studies are needed to consider them as pharmacological agents for discontinuing long-term BZD-use. In addition, specifically in the case of TPM, its side effects, especially those related to paresthesias, anorexia and difficulty with memory and concentration may limit its widespread use [32]. The same happens with OXC and TGB, agents that although they have demonstrated their efficacy in treating different anxiety disorders and SUD $[72,85,86]$, have not enough evidence for the treatment of BD and BWS $[58,59,74]$.

To sum up, to date, among AC agents, only CBZ and PGN can be considered as augmentation alternatives for the treatment of long-term BZD use. Whereas CBZ has shown to be more effective in terms of BZD-free outcomes, PGN exerts its beneficial action by reducing withdrawal and anxiety symptoms. Further randomized, double-blind, placebo-controlled studies are necessary before considering other AC agents as effective pharmacotherapies for reducing BZD withdrawal severity and achieving long-term BZD abstinence at follow-up.

\section{References}

1. Plan Nacional sobre Drogas (2012). Encuesta Domiciliaria sobre Alcohol y Drogas en España (EDADES, 2011). Madrid: Ministerio de Sanidad y Consumo.

2. Rickels K, DeMartinis N, Rynn M, Mandos L (1999) Pharmacologic strategies for discontinuing benzodiazepine treatment. J Clin Psychopharmacol 19: 1216.

3. Ashton $\mathrm{H}$ (2005) The diagnosis and management of benzodiazepine dependence. Curr Opin Psychiatry 18: 249-255.

4. Schweizer E, Rickels K (1998) Benzodiazepine dependence and withdrawal: a review of the syndrome and its clinical management. Acta Psychiatr Scand Suppl 393: 95-101.

5. Woods JH, Katz JL, Winger G (1992) Benzodiazepines: use, abuse, and consequences. Pharmacol Rev 44: 151-347.

6. Buffett-Jerrott SE, Stewart SH (2002) Cognitive and sedative effects of benzodiazepine use. Curr Pharm Des 8: 45-58.

7. Ashton $\mathrm{H}$ (1994) The treatment of benzodiazepine dependence. Addiction 89: 1535-1541.

8. Rubio G, Ponce G, Martínez-Gras I (2009) Actualización sobre la utilización de benzodiacepinas. DrugUpdate. Elsevier Doyma.

9. Voshaar RC, Couvée JE, van Balkom AJ, Mulder PG, Zitman FG (2006) Strategies for discontinuing long-term benzodiazepine use: meta-analysis. $\mathrm{Br}$ J Psychiatry 189: 213-220.

10. Schweizer E, Rickels K, Case WG, Greenblatt DJ (1990) Long-term therapeutic use of benzodiazepines. II. Effects of gradual taper. Arch Gen Psychiatry 47: 908-915.

11. Brenner PM, Wolf B, Rechlin T, Kauert G, Rüther E, Hippius H (1991) Benzodiazepine dependence: detoxification under standardized conditions. Drug Alcohol Depend 29: 195-204.

12. Sullivan M, Toshima M, Lynn P, Roy-Byrne P (1993) Phenobarbital versus clonazepam for sedative-hypnotic taper in chronic pain patients. A pilot study. Ann Clin Psychiatry 5: 123-128.

13. McGregor C, Machin A, White JM (2003) In-patient benzodiazepine withdrawal: comparison of fixed and symptom-triggered taper methods. Drug Alcohol Rev 22: 175-180.

14. Chandrasekaran PK (2008) Employing mirtazapine to aid benzodiazepine withdrawal. Singapore Med J 49: 166-167. 
Citation: Marin-Mayor M, López-Muñoz F, Rubio G (2014) Anticonvulsant Agents for the Management of Benzodiazepine Dependence. J Addict Addictv Disord 1: 003 .

15. Nakao M, Takeuchi T, Nomura K, Teramoto T, Yano E (2006) Clinical application of paroxetine for tapering benzodiazepine use in non-major-depressive outpatients visiting an internal medicine clinic. Psychiatry Clin Neurosci 60 : 605-610.

16. Ansseau M, De Roeck J (1993) Trazodone in benzodiazepine dependence. J Clin Psychiatry 54: 189-191.

17. Rickels K, Schweizer E, García-España F, Case G, DeMartinis N, et al. (1999) Trazodone and valproate in patients discontinuing long-term benzodiazepine therapy: effects on withdrawal symptoms and taper outcome. Psychopharmacology (Berl) 141: 1-5.

18. Tyrer P, Ferguson B, Hallström C, Michie M, Tyrer S, et al. (1996) A controlled trial of dothiepin and placebo in treating benzodiazepine withdrawal symptoms. Br J Psychiatry 168: 457-461.

19. Rickels K, DeMartinis N, García-España F, Greenblatt DJ, Mandos LA, et al. (2000) Imipramine and buspirone in treatment of patients with generalized anxiety disorder who are discontinuing long-term benzodiazepine therapy. Am J Psychiatry 157: 1973-1979.

20. Rynn M, García-España F, Greenblatt DJ, Mandos LA, Schweizer E, et al (2003) Imipramine and buspirone in patients with panic disorder who are discontinuing long-term benzodiazepine therapy. J Clin Psychopharmacol 23: 505-508.

21. Hallström C, Crouch G, Robson M, Shine P (1988) The treatment of tranquilizer dependence by propranolol. Postgrad Med J 64: 40-44.

22. Cantopher T, Olivieri S, Cleave N, Edwards JG (1990) Chronic benzodiazepine dependence. A comparative study of abrupt withdrawal under propranolol cover versus gradual withdrawal. Br J Psychiatry 156: 406-411.

23. Fyer AJ, Liebowitz MR, Gorman JM, Campeas R, Levin A, et al. (1988) Effects of clonidine on alprazolam discontinuation in panic patients: a pilot study. J Clin Psychopharmacol 8: 270-274.

24. Delle Chiaie R, Pancheri P, Casacchia M, Stratta P, Kotzalidis GD, et al (1995) Assessment of the efficacy of buspirone in patients affected by generalized anxiety disorder, shifting to buspirone from prior treatment with lorazepam: a placebo-controlled, double-blind study. J Clin Psychopharmacol 15 : $12-9$.

25. Cassano G, Petracca A, Borghi C, Chiroli S, Didoni G, et al. (1996) A randomized, double-blind study of alpidem vs placebo in the prevention and treatment of benzodiazepine withdrawal syndrome. Eur Psychiatry 11: 93-99.

26. Schweizer E, Case WG, Garcia-España F, Greenblatt DJ, Rickels K (1995) Progesterone co-administration in patients discontinuing long-term benzodiazepine therapy: effects on withdrawal severity and taper outcome. Psychopharmacology (Berl) 117: 424-429.

27. Romach MK, Kaplan HL, Busto UE, Somer G, Sellers EM (1998) A controlled trial of ondansetron, a 5-HT3 antagonist, in benzodiazepine discontinuation. J Clin Psychopharmacol 18: 121-131.

28. Gerra G, Zaimovic A, Giusti F, Moi G, Brewer C (2002) Intravenous flumazenil versus oxazepam tapering in the treatment of benzodiazepine withdrawal: a randomized, placebo-controlled study. Addict Biol 7: 385-395.

29. Hood S, O'Neil G, Hulse G (2009) The role of flumazenil in the treatment of benzodiazepine dependence: physiological and psychological profiles. $J$ Psychopharmacol 23: 401-409.

30. Schweizer E. Rickels K. Case WG, Greenblatt DG. (1991) Carbamazepine treatment in patients discontinuing long-term benzodiazepine therapy: effects on withdrawal severity and outcome. Arch Gen Psychiatry 48: 448-452.

31. Asconapé JJ (2002) Some common issues in the use of antiepileptic drugs. Semin Neurol 22: 27-39.

32. Johnson BA, Ait-Daoud N (2010) Topiramate in the new generation of drugs: Efficacy in the treatment of alcoholic patients. Curr Pharm Des 16: 21032112.

33. Ponce G, Rodríguez-Jiménez R, Ortiz H, Rubio G, Jiménez-Arriero MA, et al. (2005) Oxcarbazepine in the prevention of epileptic syndromes in alcohol detoxification. Rev Neurol 40: 577-580.
34. Krebs M, Leopold K, Richter C, Kienast T, Hinzpeter A, et al. (2006) Levetiracetam for the treatment of alcohol withdrawal syndrome: an open-label pilot trial. J Clin Psychopharmacol 26: 347-349.

35. Bonnet U, Banger M, Leweke FM, Maschke M, Kowalski T, et al. (1999) Treatment of alcohol withdrawal syndrome with gabapentin. Pharmacopsychiatry $32: 107-109$

36. Rubio G, Bobes J, Cervera G, Terán A, Pérez M, López-Gómez V, Rejas J (2009) Benzodiazepines use withdrawal tapering gradually with pregabalin: findings from the medical practice. Eur Neuro psychopharmacol 3: 652

37. Oulis P, Kalogerakou S, Anyfandi E, Konstantakopoulos G, Papakosta VM, et al. (2014) Cognitive effects of pregabalin in the treatment of long-term benzodiazepine-use and dependence. Hum Psychopharmacol 29: 224-229.

38. Klein E, Unde TW, Post RM (1986) Preliminary evidence for the utility of carbamazepine in alprazolam withdrawal. Am J Psychiatry 143: 235-236.

39. Ries RK, Roy-Byrne PP, Ward NG, Neppe V, Cullison S (1989) Carbamazepine treatment for benzodiazepine withdrawal. Am J Psychiatry 146: 536-537.

40. Ries R, Cullison S, Horn R, Ward N (1991) Benzodiazepine withdrawal: clinicians' ratings of carbamazepine treatment versus traditional taper methods. $J$ Psychoactive Drugs 23: 73-76.

41. Rickels K, Case WG, Schweizer E, Garcia-España F, Fridman R (1990) Benzodiazepine dependence: management of discontinuation. Psychopharmacol Bull 26: 63-68.

42. Garcia-Borreguero D, Bronisch T, Apelt S, Yassouridis A, Emrich HM (1991) Treatment of benzodiazepine withdrawal symptoms with carbamazepine. Eur Arch Psychiatry Clin Neurosci 241: 145-150.

43. Klein E, Colin V, Stolk J, Lenox RH (1994) Alprazolam withdrawal in patients with panic disorder and generalized anxiety disorder: vulnerability and effect of carbamazepine. Am J Psychiatry 151: 1760-1766.

44. Kaendler SH, Volk S, Pflug B (1996) Benzodiazepine withdrawal with carbamazepine. Nervenarzt 67: 381-386.

45. Swantek SS, Grossberg GT, Neppe VM, Doubek WG, Martin T, et al. (1991) The use of carbamazepine to treat benzodiazepine withdrawal in a geriatric population. J Geriatr Psychiatry Neurol 4: 106-109.

46. Di Costanzo E, Rovea A (1992) The prophylaxis of benzodiazepine withdrawal syndrome in the elderly: the effectiveness of carbamazepine. Double-blind study vs. Placebo. Minerva Psichiatr 33: 301-304.

47. Denis C, Fatséas M, Lavie E, Auriacombe M (2006) Pharmacological interventions for benzodiazepine mono-dependence management in outpatient settings. Cochrane Database Syst Rev19: CD005194.

48. Roy-Byrne PP, Ward NG, Donnelly PJ (1989) Valproate in anxiety and withdrawal syndromes. J Clin Psychiatry 50: 44-48.

49. Apelt S, Emrich HM (1990) Sodium valproate in benzodiazepine withdrawal. Am J Psychiatry 147: 950-951.

50. McElroy SL, Keck PE Jr, Lawrence JM (1991) Treatment of panic disorder and benzodiazepine withdrawal with valproate. J Neuropsychiatry Clin Neurosci 3: 232-233.

51. Davies A, Hendrich J, Van Minh AT, Wratten J, Douglas L, Dolphin AC (2007) Functional biology of the alpha(2)delta subunits of voltage-gated calcium channels. Trends Pharmacol Sci 2895: 220-228.

52. Maneuf YP, Gonzales MI, Sutton KS, Chung FZ, Pinnock RD, et al. (2003) Cellular and molecular action of the putative GABA-mimetic, gabapentin. Cell Mol Life Sci 60: 742-750.

53. Taylor CP (1997) Mechanisms of Action of Gabapentin. Rev Neurol (Paris) 153: $39-45$

54. Ketter TA, Frye MA, Corá-Locatelli G, Kimbrell TA, Post RM (1999) Metabolism and excretion of mood stabilizers and new anticonvulsants. Cell Mol Neurobiol 19: 511-532. 
Citation: Marin-Mayor M, López-Muñoz F, Rubio G (2014) Anticonvulsant Agents for the Management of Benzodiazepine Dependence. J Addict Addictv Disord 1: 003 .

55. Crockford D, White WD, Campbell B (2001) Gabapentin use in benzodiazepine dependence and detoxification. Can J Psychiatry 46: 287.

56. Zueco PL, Verger K, Morralla C, Hernández G (2001) Gabapentina en el tratamiento de la dependencia a benzodiacepinas en pacientes en PMM. Estudio prospectivo de 17 casos. Proceedings of the Spanish V Psychiatry National Congress, Zaragoza.

57. Wellington K, Goa KL (2001) Oxcarbazepine: an update of its efficacy in the management of epilepsy. CNS Drugs 15: 137-163.

58. Croissant B, Grosshans M, Klein O, Diehl A, Mann K (2005) Scheme-based benzodiazepine detoxification with oxcarbazepine - A case report. Pharmacopsychiatry $38: 222-223$.

59. Croissant B, Grosshans M, Diehl A, Mann K (2008) Oxcarbazepine in rapid benzodiazepine detoxification. Am J Drug Alcohol Abuse 34: 534-540.

60. Belliotti TR, Capiris T, Ekhato IV, Kinsora JJ, Field MJ, et al. (2005) Structure-activity relationships of pregabalin and analogues that target the alpha(2)-delta protein. J Med Chem 48: 2294-2307.

61. Martinotti G (2012) Pregabalin in clinical psychiatry and addiction: pros and cons. Expert Opin Investig Drugs 21: 1243-1245.

62. Guglielmo R, Martinotti G, Clerici M, Janiri L (2012) Pregabalin for Alcoho Dependence: A Critical Review of the Literature. Adv Ther 29: 947-957.

63. Biermann T, Bleich S, Kornhuber J, Hillemacher T (2007) Pregabalin in benzodiazepine withdrawal. Pharmacopsychiatry 40: 292-294.

64. Oulis P, Masdrakis VG, Karakatsanis NA, Karapoulios E, Kouzoupis AV, et al. (2008) Pregabalin in the discontinuation of long-term benzodiazepine use: a case-series. Int Clin Psychopharmacol 23: 110-112.

65. Oulis P, Konstantakopoulos G, Kouzoupis AV, Masdrakis VG, Karakatsanis NA, et al. (2008) Pregabalin in the discontinuation of long-term benzodiazepines' use. Hum Psychopharmacol 23: 337-340.

66. Oulis P, Konstantakopoulos G (2010) Pregabalin in the treatment of alcoho and benzodiazepines dependence. CNS Neurosci Ther 16: 45-50.

67. Oulis $\mathrm{P}$, Konstantakopoulos $\mathrm{G}$ (2012) Efficacy and safety of pregabalin in the treatment of alcohol and benzodiazepine dependence. Expert Opin Investig Drugs 21: 1019-1029.

68. Bobes J, Rubio G, Terán A, Cervera G, López-Gómez V, et al. (2012) Pregabalin for the discontinuation of long-term benzodiazepines use: an assessment of its effectiveness in daily clinical practice. Eur Psychiatry 27: 301-307.

69. Rubio G, Bobes J, Cervera G, Terán A, Pérez M, et al. (2011) Effects of pregabalin on subjective sleep disturbance symptoms during withdrawal from long-term benzodiazepine use. Eur Addict Res 17: 262-270.

70. Hadley SJ, Mandel FS, Schweizer E (2012) Switching from long-term benzodiazepine therapy to pregabalin in patients with generalized anxiety disorder: a double-blind, placebo-controlled trial. J Psychopharmacol 26: 461-470.

71. Pollack MH, Roy-Byrne PP, Van Ameringen M, Snyder H, Brown C, et al. (2005) The selective GABA reuptake inhibitor tiagabine for the treatment of generalized anxiety disorder: results of a placebo-controlled study. J Clin Psychiatry 66: 1401-1408.
72. Schwartz TL, Nihalani N (2006) Tiagabine in anxiety disorders. Expert Opin Pharmacother 7: 1977-1987.

73. Koob GF (2000) Animal models of craving for ethanol. Addiction 2: 73-81.

74. Oulis P, Masdrakis VG, Karapoulios E, Karakatsanis NA, Kouzoupis AV, Papadimitriou GN (2009) Tiagabine in the discontinuation of long-term benzodiazepine use. Psychiatry Clin Neurosci 63: 122.

75. White HS, Brown SD, Woodhead JH, Skeen GA, Wolf HH (2000) Topiramate modulates GABA-evoked currents in murine cortical neurons by a nonbenzodiazepine mechanism. Epilepsia 1: 17-20.

76. Gryder DS, Rogawski MA (2003) Selective antagonism of GluR5 kainate-receptor-mediated synaptic currents by topiramate in rat basolateral amygdala neurons. J Neurosci 23: 7069-7074.

77. Taverna S, Sancini G, Mantegazza M, Franceschetti S, Avanzini G (1999) Inhibition of transient and persistent $\mathrm{Na}+$ current fractions by the new anticonvulsant topiramate. J Pharmacol ExpTher 288: 960-968.

78. Zhang X, Velumian AA, Jones OT, Carlen PL (2000) Modulation of high-voltage-activated calcium channels in dentate granule cells by topiramate. Epilepsia 1: 52-60.

79. Dodson WE, Kamin M, Kraut L, Olson WH, Wu SC (2003) Topiramate titration to response: analysis of individualized therapy study (TRAITS). Ann Pharmacother 37: 615-620.

80. Cheseaux M, Monnat M, Zullino DF (2003) Topiramate in benzodiazepine withdrawal. Hum Psychopharmacol 18: 375-377.

81. Michopoulos I, Douzenis A, Christodoulou C, Lykouras L (2006) Topiramate use in alprazolam addiction. World J Biol Psychiatry 7: 265-267.

82. Johannessen SI, Landmark CJ (2010) Antiepileptic Drug Interactions - Principles and Clinical Implications. Curr Neuropharmacol. 8: 254-267.

83. Keränen T, Sivenius J (1983) Side effects of carbamazepine, valproate and clonazepam during long-term treatment of epilepsy. Acta Neurol Scand Suppl. 97: 69-80.

84. Johnson BA, Rosenthal N, Capece JA, Wiegand F, Mao L, et al. (2007). Topiramate for treating alcohol dependence: a randomized controlled trial. JAMA 298: 1641-1651.

85. Myrick H, Malcolm R, Randall PK, Boyle E, Anton RF, et al. (2009) A dou ble-blind trial of gabapentin versus lorazepam in the treatment of alcohol withdrawal. Alcohol Clin Exp Res 33:1582-1588.

86. Mason BJ, Quello S, Goodell V, Shadan F, Kyle M, et al. (2014) Gabapentin treatment for alcohol dependence: a randomized clinical trial. JAMA Intern Med 174: 70-77.

87. Martinotti G, Di Nicola M, Romanelli R, Andreoli S, Pozzi G, et al. (2007) High and low dosage oxcarbazepine versus naltrexone for the prevention of relapse in alcohol-dependent patients. Hum Psychopharmacol 22: 149-156.

88. Paparrigopoulos T, Tzavellas E, Karaiskos D, Malitas P, Liappas I (2010) An open pilot study of tiagabine in alcohol dependence: tolerability and clinical effects. J Psychopharmacol 24: 1375-1380. 